\title{
Principais Realizações do D.A.S.P. em 1956, 1957 e 1958
}

Instituição essencialmente técnica, consagrada ao estudo geral dos problemas de administração pública, tem o D.A.S.P., no atual Govêrno, prosseguido com renovado esfôrço nas tarefas de coordenação dos serviços estatais, procurando estimular sua rentabilidade e eficiência e reagir contra a inércia burocrática.

\section{PESSOAL}

$\mathrm{O}$ ano de 1956 iniciou-se com decisiva mudança da política administrativa de pessoal, tendo sido reestruturados, na forma do art. 16 da Lei $\mathrm{n}^{\circ} 2.745$, de 12 de março daquele ano, os respectivos quadros das autarquias, entidades paraestatais, Caixas Econômicas, Conselho Superior das Caixas Econômicas Federais e Instituto Brasileiro de Geografia e Estatística. Houve sensível redução dêsses quadros, condicionando-se outrossim a admissão de novos servidores à prévia e expressa autorização do Presidente da República. Paralelamente, medidas tendentes a restringir as despesas com pessoal foram adotadas com ótimas repercussões.

Cumprindo, ainda, recomendação da citada lei, providenciou o Poder Executivo, através do D.A.S.P. a elaboração do plano de classificação de cargos do serviço público federal e sua remuneração, cujo projeto foi, no prazo, submetido à apreciação do Congresso Nacional. Trabalho complexo e de vulto, levado a efeito pelo D.A.S.P. em intensivo ritmo, sem qualquer aumento de despesa.

O não provimento de cargos vagos iniciais das carreiras permitiu, desde logo, uma economia de $10,6 \%$ em relação ao total da despesa com o pagamento de vencimentos e salários de pessoal civil da União. Incluindo o não preenchimento de cargos e funções vagos nas autarquias, resultou, para o Govêrno, uma economia total de 7 bilhões de cruzeiros, nas duas áreas da administração direta e indireta, em que ficaram vagos 93.000 cargos.

No que tange ao pessoal pago por conta de verbas globais ou fundos especiais, até então constante motivo de abusos prejudiciais ao interêsse público, medidas então adotadas restringiram essas admissões, a exemplo do que fôra feito com as demais, condicionando-as também à prévia autori- 
zação presidencial. Beneficiados êsses servidores com aumento, foram também amparados de modo consentâneo com sua condição precária de emprêgo público.

A restrição de despesas com pessoal do serviço público foi de tal modo executada que apenas 470 nomeações se fizeram, o que dá a significativa média de cêrca de 40 nomeações por Ministério, e isso mesmo em virtude de concursos e provas de habilitação.

Afora essas realizações, prosseguiu ainda o D.A.S.P. nos trabalhos de que foi por lei incumbido, no setor de pessoal, de reclassificação e criação de funções classificadas; de elaboração do quadro do Ministério da Viação destinado ao pessoal da Estrada de Ferro Dona Teresa Cristina, ora em estudo no Congresso; de conceituação do status juridico do pessoal de entidades autárquicas ou paraestatais como a Superintendência do Plano de Valorização Econômica da Amazônia (S.P.V.E.A.), Comissão do Impôsto Sindical (C.I.S.), Conselho Nacional de Pesquisas (C.N.Pq.) e Institutos que lhe são subordinados, Comissão Federal de Abastecimento e Preços (C.O.F.A.P.), Serviço de Assistência Médica Domiciliar de Urgência (S.A.M.D.U.) e Administração do Pôrto de Recife (A.P.R.); organização dos quadros extraordinários das Universidades de Minas Gerais, Rio Grande do Sul, Recife, Paraná, Bahia e Ceará; alteração do quadro extraordinário da Universidade do Brasil; criação cio quadro da Rêde Ferroviária do Nordeste; estudo de todos os processos de admissão de tarefeiros e contratados, a fim de caracterizar a transitoriedade e a natureza da função a ser exercida; assessoria parlamentar da Presidência da República; complementação do Estatuto dos Funcionários Públicos, com os anteprojetos de regulamentos do regime disciplinar, de gratificação por serviços extraordinários e de assistência médico-hospitalar; atualização de normas complementares do Estatuto dos Funcionários; estudo das gratificações pagas pela participação em órgãos de deliberação coletiva; remuneração dos membros dos Conselhos Fiscais dos Institutos de Aposentadorias e Pensões; elaboração do decreto que dispõe sôbre o cancelamento de penalidades e abono de faltas não justificadas; solução dos problemas suscitados com relação às antigas emprêsas do grupo Superintendência das Emprêsas Incorporadas ao Patrimônio Nacional, pessoal das emprêsas «Armazéns Frigoríficos» e «A Noite»; elaboração de normas para o aproveitamento do Pessoal do Conselho Nacional de Petróleo em outros órgãos da administração federal, na Bahia - além da revisão e atualização dos fichários de leis e jurisprudência administrativa, do exame de questões relativas à contagem de tempo de serviço, à aplicação dos novos niveis de vencimentos, processos administrativos, penalidades e revisão, respostas a consultas sôbre aplicação de dispositivos estatutários, organização de um curso de classificação de cargos, assessoramento na Câmara e no Senado e, ainda, elaboração e tradução de literatura sôbre classificação de cargos.

O ano de 1957, que foi marcado com um fato preponderante na vida do D.A.S.P., vale dizer, a sua reestruturação expressa nos têrmos do novo Regimento, aprovado pelo Decreto $\mathrm{n}^{2} 41.955$, de 3 de agôsto do mesmo ano, se trouxe, para o Departamento, novas responsabilidades em virtude de haver determinado sua expansão na administração federal, pro- 
fundas modificações assinalou no setor de pessoal, tanto nos aspectos técnicos como jurídicos. Foi criado um Serviço de Classificação e Remuneração, com incumbência de proceder ao estudo, orientação, coordenação e documentação das atividades dos vencimentos e salários correspondentes; também se criou um Serviço Jurídico para ocupar-se dos problemas relativos ao provimento e vacância, direitos e vantagens, regime disciplinar, processo administrativo e sua revisão; e, por fim, um Serviço de Cadastro, com atribuições de contrôle dos registros relativos a cargos e funções da administração indireta.

O D.A.S.P. ocupou-se ainda, no decorrer dêsse ano, de processos de caráter geral e da elaboração de anteprojetos regulamentares. São de consignar-se os anteprojetos convertidos em decretos executivos dispondo sôbre o aproveitamento, no serviço público, do pessoal do grupo da Superintendência das Emprêsas Incorporadas ao Patrimônio Nacional (S.E.I.P.N.) dando total cumprimento ao estabelecido nas Leis ns. 2.193-53 e 2.904-56; os estudos relativos ao aproveitamento dos funcionários em disponibilidade dos territórios extintos; o levantamento geral das possibilidades do reemprêgo, em órgãos públicos, dos servidores dos Bancos em liquidação extrajudicial; a complementação do Estatuto dos Funcionários, isto é, a regulamentação dos dispositivos concernentes às gratificações pelo exercicio em determinadas zonas ou locais, pela execução de trabalho de natureza especial, com risco de vida ou saúde, pela participação em órgão de deliberação coletiva; das vantagens especiais dos servidores que operam com Raios X e substâncias radioativas - afora o prosseguimento do exame dos quadros e tabelas das autarquias e situação do pessoal autárquico, pessoal temporário, custeado por dotações globais.

A política de limitação das admissões ao serviço público também continuou a ser observada, estendendo-se tanto na área da administração direta como na da administração descentralizada.

No que concerne aos candidatos habilitados em concurso, a politica adotada pelo Govêrno é no sentido de nomeá-los tanto quanto possível sem aumento de despesa, para as vagas decorrentes de exoneraçốes.

Em 1957, o número de servidores egressos da administração, sobretudo por meio de aposentadorias, foi superior em 703 aos dos que entraram nas carreiras e séries funcionais: o número de nomeações atingiu a 2.833 , dos quais 92 nomeados em comissão, 59 em substituição e 1.361 em virtude de concurso, sendo que 1.321 nomeações foram interinas. No entanto, 3.536 funcionários saíram do serviço público, sendo 2.881 por meio de aposentadorias, 460 por exonerações, 147 por falecimentos e 48 por demissões.

A restrição no preenchimento de cargos continuou a proporcionar redução de gastos no montante de $\operatorname{Cr} \$ 1.488 .670 .200,00$, sendo, além disso, extintas 15.362 funções de extranumerários, resultando a medida numa economia anual de Cr\$ 903.760.800,00.

O D.A.S.P. preparou, ainda, os trabalhos de aproveitamento do pessoal de diversos estabelecimentos de ensino federalizados (Faculdade de Direito de Niterói, Universidade Rural de Pernambuco, Conservatório 
Mineiro de Música, Instituto de Eletrotécnica de Itajubá, Escola Paulista de Medicina e Faculdade de Direito da Universidade da Bahia). Numerosas questões foram levantadas pelos órgãos ministeriais e autárquicos no tocante à interpretação de dispositivos estatutários e combinação dêstes com outros diplomas legais, tendo sido também numerosos os pronunciamentos sôbre questões de regime disciplinar.

Neste ponto, cabe chamar atenção para o fato de que a movimentação de processos é realmente intensíssima.

O ano de 1958 foi assinalado pela adoção de diversas medidas moralizadoras e de austeridade que vieram pôr em evidência o empenho do Govêrno na preservação do regime, evitando, por meio de providências acauteladoras, qualquer influência da máquina estatal nas eleições. O Decreto $\mathrm{n}^{\circ}$ 43.716, de 19 de maio, vedou as admissões e nomeações de servidores na administração pública centralizada e autárquica, tendo sido prorro gada a providência até abril de 1959 pelo Decreto n. $^{\circ} 44.606$, de 4 de outubro.

Na mesma ocasião, e ante o mesmo motivo das eleições, o Govêrno providenciou o afastamento de seus cargos de todos os diretores e chefes de repartições que fôssem candidatos a mandato eletivo. Ainda outras providências, de caráter moralizador, traduziram a absoluta isenção do Govêrno em relação ao pleito, tais como a suspensão dos financiamentos no período pré-eleitoral por parte dos Institutos de Previdência e Caixas Econômicas Federais, a proibição de uso de veículos oficiais em campanha eleitoral e o cuidado e empenho em evitar o empreguismo, suspendendo-se, outrossim, as aquisições de material permanente e de consumo para o serviço público, ressalvados os casos de estrita necessidade e premência.

Novamente resultou, dessa política antiempreguista, que o número de admissões e nomeações em 1958 foi de 4.169 , inferior ao de vagas verificadas, 4.971, êste número excedendo aquêle em 802 .

Levando adiante o trabalho de regulamentação do Estatuto dos Funcionários, foi ultimado o preparo da regulamentação das gratificações por exercício em determinadas zonas ou locais e por execução de trabalho de natureza especial, com risco de vida ou saúde, inclusive quanto aos servidores do Departamento Federal de Segurança Pública, quando em ação contra criminosos. Também foi revista, no concernente a servidores civis, a regulamentação da Lei $n^{\circ} 1.234$, de 14 de novembro de 1950 , conferindo vantagens especiais aos servidores que operam com Raios X e substâncias radioativas.

O Govêrno prosseguiu em 1958 nos trabalhos tendentes a estender às autarquias as normas de pessoal vigentes para os Ministérios e Órgãos subordinados à Presidência da República, regularizando a concessão de vantagens a êsses servidores e instituindo tabelas para as autarquias que não as possuiam. Organizou-se o cadastro do pessoal das autarquias e criaram-se os Boletins de Pessoal dessas entidades. Êsse boletim é de extraordinário alcance no sentido da moralização administrativa, facilitando a divulgação, para a opinião pública, dos atos de seus dirigentes.

Assim, em matéria de pessoal, representa o ano de 1958 notável progresso moralizador. 
No tocante ao plano de classificação de cargos, em tramitação no Legislativo, apesar das insistentes lutas no sentido de torná-lo em realidade, o Govêrno, ante as conhecidas dificuldades financeiras que não lhe permitiriam arcar com as despesas de sua integral aplicação total de imediato, adotou fórmula dividindo sua implantação em duas fases. Foi, pois, concedida uma espécie de adiantamento da ordem de $30 \%$ ao funcionalismo civil a ser classificado, fazendo-se o ajustamento de vencimentos na forma dos níveis estabelecidos na data da vigência do plano, a ocorrer futuramente.

\section{TRANSFERÊNCIA DE PESSOAL E DE ÓRGÃOS PARA BRASÍLIA}

O Decreto $n^{9} 43.285$, de 25 de fevereiro de 1958, instituiu junto ao D.A.S.P. um grupo de trabalho composto de representantes dos Ministérios civis e militares, do Estado Maior das Fôrças Armadas e da NOVACAP, com a finalidade de promover as indispensáveis providências relacionadas com a transferência, para a futura capital, dos órgãos federais. Instalado a 14 de março do ano passado, êsse grupo de trabalho realizou 19 reuniões plenárias, tendo apresentado os primeiros resultados de seus estudos, a 28 de outubro de 1958, fixando os quantitativos progressivos de pessoal a ser transferido e, bem assim, estabelecendo dados e definições sôbre a instalação de órgãos federais, transporte de funcionários com dependentes e pertences, de material e equipamentos para as repartições, abastecimento de material permanente e de consumo. Seguir -se-á em 1959, já em andamento, aliás, a fase de ação executiva pertinente ao programa de transferência de pessoal e órgãos, a ser ainda no corrente ano concretizada.

O Grupo de Trabalho de Brasilia já organizou, em cooperação com a Rêde Ferroviárịa Federal, três viagens experimentais de trem Rio-Anápolis, em datas de 20 de julho, 27 de setembro e 23 de novembro de 1958, a fim de estudar os itinerários mais favoráveis. Encontra-se programada a ida de um quarto trem, agora, em princípio de 1959, após o que serão estabelecidos trens regulares. O trem de Brasilia comprovou o entusiasmo e a viabilidade do trânsito ferroviário regular entre o Rio e a nova capital.

Tämbém os Podêres Legislativo e Judiciário designaram seus representantes junto ao Grupo de Trabalho, nas tarefas de entrosamento encetadas pelo mesmo. No momento, êsse Grupo está instalando o seu escritório em Brasília, a fim de receber as residências construídas pelos Institutos de Previdência, Caixa Econômica Federal e Fundação da Casa Popular, destinadas aos servidores civis e militares que forem designados para servir naquela cidade.

\section{SELEÇÃO E APERFEIÇOAMENTO}

No que diz respeito à seleção e aperfeiçoamento de pessoal, realizou o D.A.S.P., em 1956, 28 concursos, abriu inscrição para 24 e prosseguiu com seus cursos regulamentares, isto é, os básicos (preparo de pessoal destinado às atividades auxiliares da administração), os extraordinários (atividades técnicas específicas) e por correspondência, além de promover conferências sôbre administração geral, cursos sôbre administração de cargos e de linguas inglêsa e francesa. 
Em 1957, apesar da politica de contenção de gastos, não sofreram solução de continuidade as atividades de recrutamento e seleção de pessoal para as carreiras. Patenteada a urgência de regularizar-se a situação dos interinos, pôsto que o art. 12 do Estatuto dos Funcionários não permite que os mesmos permaneçam nos cargos por período superior a dois anos, foi o D.A.S.P. autorizado a realizar concursos exclusivamente para carreiras onde houvesse interinos.

Dificuldades materiais oriundas do problema de mudança de instalações não permitiram funcionassem os cursos de aperfeiçoamento do D.A.S.P. do modo desejado, na forma habitual de seu programa traçado para o currículo de 1957. O calendário foi alterado, começando os cursos básicos em junho e os especializados em setembro. Também os cursos extraordinários de inglês tiveram prosseguimento a partir de julho, tendo tido o curso de correspondência, a seu turno, bons resultados.

O sistema do mérito foi plenamente revigorado em 1958, tendo 59.343 candidatos sido chamados à prova, dos quais 2.549 lograram habilitação. Do mesmo modo, incrementou o Govêrno o sistema de aperfeiçoamento de servidores no país e no estrangeiro, fundando, para êsse fim, a Escola do Serviço Público, que já está funcionando em regime de acôrdo entre o D.A.S.P. e o Ministério da Educação e Cultura, segundo o Decreto $\mathrm{n}^{\circ}$ 43.176, de 4 de fevereiro de 1958. Intensificam-se, com essa nova entidade, os trabalhos de aperfeiçoamento de pessoal, com treinamento intensivo e amplo de servidores, atendendo às necessidades dos serviços públicos.

No ano próximo findo, instituiu-se, nessa escola, o Curso Técnico de Administração, regulado pelo Decreto-lei n $\mathrm{n}^{\circ}$ 6.141, de 1943 (Lei Orgânica do Ensino Comercial), para formação de pessoal qualificado de nível médio, dando aos que o completarem direito ao diploma de assistente de administração. Freqüentaram o primeiro ano 61 alunos, distribuídos por duas turmas.

Foram, ainda, planejados cursos de administração orçamentária, de pessoal, material, administração de emprêsas, contabilidade pública, correspondência e estenografia, correspondência e redação oficial, direção e gerência de serviços, direito usual, economia, finanças, organização de serviços públicos, relaçôes humanas no trabalho, relações públicas, sociologia, técnica de distribuição e transportes e tecnologia de material.

Houve intenso trabalho no setor de cursos avulsos, em matéria de administração, que funcionaram em regime de colaboração do D.A.S.P. com outros órgãos da administração federal.

\section{ELABORAÇÃO ORÇAMENTÁRIA}

Tem o D.A.S.P. regularmente exercido sua atribuição de elaborar a proposta orçamentária, no atual Govêrno, mediante pesquisa minuciosa e estudo das propostas parciais de despesas apresentadas pelas repartições, com o ajustamento dos programas de trabalho que essas propostas encerram.

Inovação introduzida em 1956 foi a adoção de novos métodos de trabalho, de modo que a proposta elaborada para o exercício de 1957 representou a tradução, em quadros discriminativos da despesa, do custo dos 
programas de trabalho de cada repartição. O levantamento de dados estatísticos e contábeis permitiu a previsão da receita, indicando-se a influência da política financeira na economia nacional e o aperfeiçoamento dos métodos de estimativa das rendas públicas, bem como novas fontes de renda, para atender a serviços extraordinários ou especiais.

Cuidou o D.A.S.P., por êsse seu setor de atividades, da padronização dos critérios gerais de orçamentos, balanços e demonstrações de contas das autarquias federais, afora o preparo e execução do plano de economia, que por condições várias emergentes não foi executado integralmente em 1956 ocorrendo a liberação de $15,75 \%$ das dotações então congeladas. Tais liberações derivam de expedientes cujo estudo obriga a realização de várias pesquisas.

As atividades de 1957 ativeram-se aos mesmos setores, isto é, além da elaboração do Orçamento para o ano seguinte, acompanhamento da execução orçamentária então vigente, através do exame dos planos de aplicação das dotações globais e dos planos de contenção de despesas, emissão de pareceres sôbre abertura de créditos adicionais, concessão de adiantamentos, e outros; exame de processos relacionados com o último orçamento, sob a forma de «restos a pagar»; e, ainda, os planos de aplicação destinados a orientar a contenção de despesas no setor orçamentário, além dos estudos dos orçamentos das autarquias.

Se, pela legislação vigente, são as repartições obrigadas a apresentar, anualmente, à aprovação presidencial, seus programas de trabalho, entendeu o Govêrno de conjugar êsses programas de trabalho com os planos de aplicação do crédito orçamentário respectivo. Foi estendida, assim, a tôdas as repartições a obrigação de apresentarem seus planos de aplicação de tôdas as dotações globais, sujeitando-os à aprovação do Presidente da República, resultando, destarte, possivel obter-se uma especialização dos gastos vinculados a essas dotações globais, para o fim de uniformizar-se a utilização dêsses recursos nos ministérios. A medida de contrôle administrativo a priori da execução orçamentária vem mais firmemente caracterizar o programa de trabalho do Govêrno, expresso na boa execução orçamentária, uma vez que ficam sem aplicação os recursos vinculados a dotações globais sem prévia aprovação presidencial. Serviram, também, êsses planos para descobrir a existência de dotações em que as despesas de pessoal excedem de $70 \%$. 183 planos, desdobrados em 397 programas, foram examinados em 1958, no total superior a 14 bilhões de cruzeiros.

Tem-se esforçado o Govêrno no sentido de conter o deficit cujo agravamento estava previsto para o exercício de 1959. Assim, para êsse exercício foi elaborada e apresentada ao Congresso Nacional uma Proposta equilibrada, a qual foi revista, posteriormente, face à ocorrência de circunstâncias imprevisiveis, na forma do Plano de Estabilização Monetária, que tenta reduzir o deficit de Caixa. Para reduzir a níveis suportáveis a taxa de inflação, foram utilizados mecanismos de natureza administrativa capazes de colocar a despesa dentro do fluxo real da receita (planos de contenção de despesas e outras modalidades de planejamento de execução orçamentária, como seleção de investimentos, hierarquização do custeio, etc.). A con- 
tingência de 1958 obrigou o Govêrno a elaborar um plano de contenção de despesas no total de 17 bilhões de cruzeiros.

Como, ainda assim, a receita arrecadada se mostrava insuficiente para fazer face aos pesados encargos do tesours, dadas as despesas de créditos e fundos especiais, de "restos a pagar» e dos arts. 46 e 48 do Código de Contabilidade, o meio de contenção de que lançou mão o Govêrno consistiu em elaborar, nessa oportunidade, um Fundo de Reserva de 10 bilhões de cruzeiros, cuja liberação das despesas nêle contidas fica, em princípios, sujeita à compensação de outros recursos não utilizáveis pela administração ou à rentabilidade efetiva da receita pública.

Pela primeira vez foram adotadas medidas objetivas de planejamento da execução orçamentária e extraorçamentária. O Decreto $\mathrm{n}^{\circ} 44.058$, de 22 de julho de 1958, fixou os niveis ministeriais de constituição do referido Fundo de Reserva.

O problema da padronização de orçamentos e balanços das autarquias foi objeto de novos e acurados estudos pelo D.A.S.P., em 1958. Com a colaboração de vários especialistas na matéria, inclusive professôres universitários, elaborou-se novo padrão de Orçamento e Balanço para as autarquias, em moldes semelhantes aos adotados no Orçamento Federal. O anteprojeto vai além dos limites das administrações paraestatais, visando a atingir inclusive as entidades colaboradoras da administração federal, como o S.E.S.C., S.E.N.A.C., S.E.S.I. e S.E.N.A.I., além de outras, para vigorar em 1959.

\section{ORGANIZAÇÃO E DOCUMENTAÇÃO ADMINISTRATIVA}

Em 1956, elaborou e publicou o D.A.S.P. nova edição do «Indicador da Organização Administrativa Federal», sintese informativa da situação das repartições públicas federais. Também foram atendidos e elaborados, entre outros, os regimentos da Divisão de Higiene e Segurança do Trabalho, Diretoria de Rendas Internas, Divisão de Educação Física, Instituto de Óleos e Hospital dos Servidores do Estado (alteração do regimento), Departamento Nacional de Endemias Rurais, Departamento de Administração do Ministério da Educação e Cultura, Instituto Superior de Estudos Brasileiros (reforma) e Serviço de Estatistica do Ministério da Educação e Cultura (consulta sôbre funções gratificadas).

Além do exame pelo D.A.S.P., no período mencionado, da estrutura de numerosas repartições, no sentido de adequar seus respectivos regimentos, é de destacar-se a descentralização do pagamento do funcionalismo, a instituição do decreto coletivo, a padronização e simplificação do processo de aposentadoria dos servidores da União e a descentralização dos serviços da Recebedoria.

No tocante à divulgação e documentação administrativa, lançou ainda o D.A.S.P., entre 1956 e 1958, trabalhos do maior alcance e aceitação, como «O Relatório Técnico sôbre a Nova Capital», o «Ementário de Decisões Administrativas», a «História Administrativa do Brasil» e, além de numerosas outras obras e da manutenção da Revista do Serviço Público com 
projeção internacional, os volumes «Os Vencimentos no Serviço Público Federal» e «A Mulher no Serviço Público Federal», análises estatísticas e sociais de caráter pioneiro no continente. $E^{\prime}$ de salientar que, entre 1956 e 1958, o Serviço de Documentação do D.A.S.P. publicou em média um livro por semana.

\section{OBRAS E EDIFÍCIOS PÚBLICOS}

As atividades do D.A.S.P., no setor de obras e edifícios públicos, importaram, em 1956, no exame e revisão de projetos oriundos dos Ministérios e nos serviços de cooperação com outros órgãos da administração, compreendendo tanto a elaboração de projetos como o estudo e os pareceres sôbre obras públicas. Duzentos e sete processos tramitaram por sua Divisão especializada, num valor global de orçamentos de trabalhos analisados que atingiu a $\operatorname{Cr} \$ 389.143 .435,00$. Também os estudos relativos à mudança da capital ocuparam instantemente seu trabalho.

Nos anos de 1957 e 1958, concentrou a Divisão de Edifícios Públicos do D.A.S.P. sua atenção nos projetos e construção das Cidades Üniversitárias das Universidades do Rio Grande do Sul e do Paraná além de colaborar com as Universidades de Minas Gerais e diversos órgãos da administração, especialmente a NOVACAP, atuando como entidade de orientação e normalização das construções de edifícios públicos.

\section{ESCRITÓRIO TÉCNICO DA UNIVERSIDADE DO BRASIL}

Órgão transitório de planejamento e execução de obras da Universidade, êsse eșcritório prosseguiu seus trabalhos no decorrer dos três anos do atual Govêrno, dentro das dotações orçamentárias previstas, ocupando-se dos pavilhões do Hospital de Clinicas, da Faculdade de Arquitetura e da Escola Nacional de Engenharia, além da Ponte Osvaldo Cruz e da pavimentação da avenida principal. 
Recebemos e agradecemos

Amérì̀as - Vol. X - N. 10 - Outubro 1958. - Rio de Janeiro. Vol. X N. 11 - Novembro 1958 - Rio de Janeiro.

Anais do Conselho Nacional de Educação Vol. II - Ano 1952 - Rio - Brasil. Vol. I - Ano 1953 - Rio - Brasil.

Antário de Jurisprudência - Tribunal Maritimo - Ano 1951 - Vol. IX - Rio de Janeiro. Ano 1953 - Vol. XI - Rio de Janeiro. Ano 1952 - Vol. X - Rio de Janeiro.

Boletim - Pioneiras Sociais - Vol. 1 N. ${ }^{\circ} 2$ - setembro 1958. Vol. 1 N. 3 - outubro 1958. Vol. 1 N. 1 - agôsto 1958.

Boletim Britânico - Ano XI - Londres Outubro 1958 - N. ${ }^{\circ}$ 120. Ano XI Londres - Dezembro 1958 - N. 121.

Boletim do Departamento Nacional de Educação - Ano 1 - Agĉsto 1958.

Boletim de la Dirección General Impositiva - Vol. 9 - Agôsto 1958 - N. 56 - Ano V. Buenos Aires, Argentina. Vol. 9 - Octubre 1958 - N. ${ }^{\circ} 58$ Ano V - Buenos Aires, Argentina.

Boletim Estadistico - 1 Primer trimestre 1958 - Argentina.

Boletim Mensal do Banco do Brasil - Ano VIII - Agôsto, setembro 1958 - Ns. 1 e 2 .

Boletim Mensal da Federação das Induistrias do Distrito Federal - N. 8 - Ano 1 - N. 49 - Dezembro 1958 - Rio de Janeiro.

Boletim Mensal - Vol. IV - N. 7 - Julio de 1958.

Boletim de Pessoal - Ano VII - 10 dezembro 1958 - N. ${ }^{\circ}$ 635. Ano VII 29 dezembro 1958 - N. 433.

Boletim de Revistas - Ano 3 - Vol. 3 N. 1.

Boletim Técrico do Instituto Agronômico do Norte - N. ${ }^{\circ} 33-1958$ - Belém Pará - A junta amazônica.

Boletim da Universidade do Ceará - N.`11 - Março e abril 1958 - Fortaleza.
Brasil - Censo Comercial e dos Serviços I.B.G.E. - Vol. III. Transportes e Comunicações - Vol. IV.

Catalogo de la Biblioteca - Buenos Aires 1958 - Chronique de L'Organisation Mondiale de la Santé - Vol. 12 N. 10 - Octobre 1958 - Vol. 12 N. 11 - Norembro 1958.

Comércio Exterior de la Republica Dominicana - Vol. VI - N. 2 - Febrero 1958.

Comunications - July 1958.

Deficits e Superavits - 1958 - Targino Seara.

A Defesa Nacional - Ano XLVI -.. Ns. 532 e 533 - Novembro e dezembro 1958 - Ministério da Guerra - Rio de Janeiro.

Departamento Nacional de Educação Ano I - Rio de Janeiro - agĉsto 1958 - N..$^{\circ}$ I - Rio de Janeiro - Setembro $1958-\mathrm{N} .^{\circ} 9$.

Departamento Administrativo do Serviço $p_{u}$ iblico - Ano 3 - Vol. 3 - N. 12 .

Documentacion Administrativa - N. 11 Madrid - Noviembre 1958.

Economic Leaflets - Vol. XVII - N: 10 - October - 1958 - Vol. XVII N. 9 - Ceptember 1958.

Estatuto do 《Leef》 - N. ${ }^{\circ} 1$ - Novembro 1956.

I.P.A.S.E. - Ano XII - N. 56 - Maio, junho 1958 - Rio de Janeiro.

The Journal for Administrators and Departament Heads - Vol. 86 - Decembre 1958 N. 6.

Tutisprudência e Doutrina - N. ${ }^{\circ} 31$ - Julho, agôsto e setembro 1958 - Fortaleza.

Iornal Oficial do Municipio de Ithéus Ano XXI - 69. $0^{\circ}$ da República N. ${ }^{\circ} 2.012$ - Sexta-feira 22-8-58.

L'Éradication ou Palodisme - Genéve 1958 - Palais des Nations.

Legislação Específica de Pessoal - Separata da «Revista do Serviço Público» - 1949 - Rio de Janeiro - Brasil.

Mensário Estatistico - N. ${ }^{\circ} 86$ - Agôsto 1958 - Rio de Janeiro - Brasil N. 86 - Julho 1958 - Rio de Janeiro, 
Brasil - N. ${ }^{\circ} 88$ - Outubro 1958 - Rio de Janeiro, Brasil - N. 89 - Novembro 1958 - Rio de Janeiro - Brasil.

Mundo Estudantil - Vol. 12 - N. ${ }^{\circ} 8$ 1958.

News of the Utrecht Trade Tair Nouvelles de la Faire D'Autrecht Nachrichteu der Messe - N. ${ }^{\circ} 58$ - Vol. IX - a September, 1958.

Noticiário Espanhol - N. 13 - Julho 1958 - aMdrid.

Noticuiário das Nações Unidas - Ano VIII - N. 9 - Setembro 1958 - Rio de Janeiro.

Noticias Municipais - Ano V - N. $29-$ Julho, agôsto de 1958 - Ano V - N. 31 - Novembro e dezembro de 1958.

Noticias de Portugal - N. 594 - 20-9-59 - Ano XII - Palácio da Foz - Portugal. N. ${ }^{\circ} 595-27-9-59-$ Ano XII - Palácio da Foz - Portugal. N. ${ }^{\circ} 598$ - 18-10-58 - Ano XII - Palácio da Foz - Portugal. N. ${ }^{\circ} 600-1-11-58-$ Ano XII. N. ${ }^{\circ} 599-25-10-58$ - Ano XII - Palácio da Foz - Portugal. N. ${ }^{\circ} 404-29-11-58$ - Ano XII - Palácio da $\mathrm{Foz}$ - Portugal. N. $607-$ 20-12-58 - Ano XII - Palácio da Foz - Portugal. N. $608-27-12-58$ - Ano XII - Palácio da Foz - Portugal.

O Fôro Militar - Rio de Janeiro - 1958.

O Lingoter - Ano VI - Outubro 1958 - N. 118.

Padrão de Vida do Operário Industrial de Pôrto - N. $^{\circ} 2-1958$.

Paraná Econômico - Ano VI - N. 68 Novembro 1958 - Estado do Paraná. Ano VI - N. 69 - Dezembro 1958 - Estado do Paraná.

Realidade Econômica - Ano 1 - N. 9 .1958

Relaciones Trabajos - N. 89 - Julho, 1958.

Revista Associação Comercial de Minas Ano VII - Outubro de 1958 - N. ${ }^{\circ} 70$; Ano VII - Agôsto de 1958 - N. 68.

Revista Brasileira de Odontologia - Vol. lume 16 - Juho, agôsto 1958 - N. 91.

Revista da Campanha Nacional de Educação Rural - Ano 4-1957; ano 5 - 1958; ano VII - Julho, agôsto 1958 - N. ${ }^{\circ} 4$.

Revista do Club Municipal - Ano 1958 novembro - N. ${ }^{\circ} 217$.

Revista do Conselho Nacional de Economia - Ano VII - Julho, agôsto 1958 N. ${ }^{\circ} 4$.
Revista de La Facultad de Derelzho y Ciências Sociales - Ano IX - Janeiro, marzo, 1958 - N..$^{\circ}$.

Revista Fluminense de Estatistica - Ano 1 - Janeiro, junho, 1958 - N. 1.

Revista Forense - Vol. 176 - Ano 55 Fasciculos 657 e 658 - Março e abril de 1958.

Revista del Foto - Ano XLIV - Setiembre, dicembre 1957 - N. ${ }^{\circ}$ 3; Ano XLV Enero, abril - 1958 - N. ${ }^{\circ} 1$.

Revista do I.R.B. - Ano XIX - N. 112 - dezembro 1958.

Revista de Intendência da Aeronáútica Ano IX - N. ${ }^{\circ} 72,75$ - Setembro, dezembro, 1957 - Rio de Janeiro.

Revista Militar Brasileira - Ano XLVI Ns. 1 e 2 - Julho 1958 - Vol. LXVII - Rio de Janeiro (janeiro, mês).

Revista Municipal de Engenharia - Vol. XXV - Janeiro, junho, 1958 - 1 e 2 - Rio de Janeiro.

Revista Municipal - Arte e Letras Khoma - Ano VII - Vol. II - Ns. 31 e 32 - La Paz, Bolivia.

Revista Paulista de Contabilidade - Ano XXXVI - Julho, agĉsto, 1958 - Número 382.

Revista dos Tribunais - Vol. $57-\mathrm{N} \cdot{ }^{\circ} 3$ - maio, junho 1958 - Bahia.

Revista de la Universidad - N. 4 - Re. pública Argentina.

Revue Internationale des Sciences Administrative - Vol. XXIV - N. 3-1958Bruxelas - Bélgica.

Rodovia - Ano XX - Fevereiro 1958 N. ${ }^{\circ} 216$ - Rio de Janeiro - Ano XX - Março 1958 - N. 217 - Rio de Janenro - Ano XX - Abril 1958 N. ${ }^{\circ} 218$ - Rio de Janeiro - Ano XX - Maio 1958 - N. 219 - Rio de Janeiro - Ano XX - Junho 1958 N. ${ }^{\circ} 220$ - Rio de Janeiro.

Saude - Ano XI - Fevereiro 1958 N. ${ }^{\circ} 122$ - Rio de Janeiro - Ano X Dezembro 1957 - N. ${ }^{\circ} 120$ - Rio de Janeiro.

The New England Journal of Medicine Vol. 259 - Outubro 1958 - N. 17.

Trojan in Government - Vol. XIV - N. 2 - October 1958.

Vida Universitária - Ano IX - Ns. 90 e 91 - Enero, ferero 1958 - Ano IX - Ns. 92 e 93 - Marzo, abril 1958 - La Habana.

Waine State University - Vol. II - October $1958-\mathrm{N}^{\circ} 1$. 


\section{COLABORAM NESTE NÚMERO}

Alfredo Balthazar da Silveira - Bacharel em Direito pela antiga Faculdade Livre de Direito da cidade do Rio de Janeiro. Adjunto de Promotor e Curador de Orfãos (interinamente) no Rio. Catedrático de História, do Instituto de Educação, durante 39 anos. Colaborador de diversos jornais e revistas técnicas. Autor de várias obras, destacando-se $\ll \mathrm{Di}$ reito de Asilo», «Homologação de Sentenças Estrangeiras», «Segredo Profissional», "Contra a Regulamentação do Jôgo», «Direitos da Mulher» e «Imunidades Parlamentares». Escreveu também várias biografias de personalidades brasileiras.

Araujo Cavalcanti - Técnico de Adm1nistração do D.A.S.P.; ex-Membro do Conselho Nacional de Pesquisas; ex-Diretor da Divisão de Organização e Orçamento do D.A.S.P.; ex-Diretor do Serviço de Documentação do D.A.S.P.; Membro do Conselho Consultivo do Banco do Nordeste; do Conselho de Administração do I.B.A.M. e do Conselho Deliberativo da A.B.M.; Chefe da Assessoria Técnica do $\mathrm{V}$ Congresso $\mathrm{Na}$ cional dos Municipios Brasileiros; Secretário Geral do Instituto Brasileiro de Ciências Administrativas; Membro da CRIFA; etc. Recentemente indicado para fazer os Cursos da Escola Superior de Guerra (Ano letivo de 1959).

MARIA VIDO - Bibliotecária diplomada pelos Cursos de Biblioteconomia da Biblioteca Nacional do Rio de Janeiro. Contemplada com uma Bôlsa de Estudos pelo Instituto de Cultura Hispânica de Madri (1956-1957), a fim de aperfeiçoar os seus conhecimentos de Biblioteconomia e Documentação. Além dos cursos que freqüentou na Espanha, estagiou e estudou nas principais Bibliotecas e Centros de Documentação da França, Itália $€$ Portugal, conquistando um total de 11 titulos. Possui ainda Certificados dos Cursos de Extensão Universitária de $\mathrm{He}$ ráldica e Literatura (Universidade do Brasil e Academia Brasileira de Letras).

Elza Robillard de Marigny - Oficial Administrativo por concurso, pertencente ao quadro do Ministério da Fazenda. Possui os seguintes Cursos da American University, Washington, D.C.: «Income Tax Procedures, Public Finance and Taqation e Introduction to Government Accoutings, e Principles of Public Administration. Cursou em $1955-56$ a E.B.A.P. da Fundação Getúlio Vargas, graduandose em Técnico de Administração. 